\title{
AN EXPERIMENTAL EVALUATION OF TFL/LTR CONTROLLERS AGAINST ACTUATOR FAILURE AND TIME DELAY APPLIED IN A 3DOF HELICOPTER
}

\author{
Moritz Arndt Hemmann*, Renan Lima Pereira ${ }^{\dagger}$, Karl Heinz Kienitz $^{\dagger}$ \\ * Technische Universität Hamburg-Harburg, Germany. \\ ${ }^{\dagger}$ Instituto Tecnológico de Aeronáutica, Divisão de Engenharia Eletrônica, \\ 12228-900 São José dos Campos, SP, Brasil.
}

Emails: moritz.hemmann@tuhh.de, renanlimaster@gmail.com, kienitz@ita.br

\begin{abstract}
This paper presents an application of robust controllers in a laboratory helicopter system. The controllers were designed using the TFL/LTR (Target Feedback Loop/Loop Transfer Recovery) technique with amplified linear quadratic regulation (ALQR). The purpose of the designed control system is to solve the problem of tracking reference trajectories ensuring performance and stability in spite of motor power loss and time delay at the input of the plant. The laboratory helicopter is a nonlinear system, but it's dynamic is approximated by a $6^{\text {th }}$ order linear model. The helicopter attitude is described by three angles: travel $\phi$, elevation $\psi$ and pitch $\theta$. Experimental results obtained with the robust controllers in the presence of actuator failure and time delays are presented.
\end{abstract}

Keywords- Robust control, TFL/LTR controllers, 3DOF helicopter, Actuator failure, Time delay.

\begin{abstract}
Resumo - Este artigo apresenta a aplicação de controladores robustos em um helicóptero de laboratório. Os controladores foram projetados usando a técnica TFL/LTR (Target Feedback Loop/Loop Transfer Recovery) com regulação linear quadrática amplificada (ALQR). A proposta consiste em resolver o problema de rastreamento de trajetórias de referência, garantindo desempenho e estabilidade apesar de perda de potência dos motores e atrasos na entrada da planta. A dinâmica da planta é descrita por um modelo linearizado de $6^{a}$ ordem. Os três graus de liberdade são: deslocamento $\phi$, elevação $\psi$ e arfagem $\theta$. Resultados experimentais são apresentados usando os controladores robustos quando submetidos à falhas nos atuadores e atrasos.
\end{abstract}

Keywords - Controle robusto, Controladores TFL/LTR, Helicóptero 3DOF, Falha no atuador, atraso no tempo.

\section{Introdução}

Robust control design is an important part in control system research. In literature one finds many different methods of robust control system design (Da Cruz, 1996), (Skogestad and Postlethwaite, 2001). The target feedback loop/loop transfer recovery (TFL/LTR) design is one of them. In the past it was successfully used to control a varied class of systems.

The objective of robust control is to determine control strategies that are capable to tolerate mismatches between the nominal model and the real plant. Some factors may result in such mismatch, for example errors due to linearization (small-signal modeling), variation of the operating point of the plant (from the one used in modeling) and faults in the system.

The term "fault" designates any impairment of system components that may result in performance degradation or even a complete stop of system functions. System faults can be classified as sudden (abrupt faults) or incipient faults (when the system suffers a slow degradation). Implementing a fault tolerant system, that keeps its dynamic response inside acceptable limits even under fault occurrence, is not trivial. In such case, the system can have its performance degraded but must continue to be operational.
There are several proposed solutions to the fault tolerant control problem. The proposal of this paper is to evaluate the TFL/LTR (Target Feedback Loop/Loop Transfer Recovery) robust control design via Amplified Linear Quadratic Regulator (ALQR) in a laboratory helicopter system with abrupt faults caused by power loss and time delay in the communication with the actuators. The novelty consists in evaluating the ALQR approach for loop transfer recovery.

The organisation of this paper is as follows: In Section 2 the development of the 3DOF helicopter model is presented. Section 3 presents the TFL/LTR method. Section 4 describes the design of the robust controllers and section 5 presents the experimental results and discussions. Finally, section 6 contains the conclusion.

\section{Description of the 3DOF Helicopter}

The robust control method is applied to a three degree of freedom helicopter named "3DOF Helicopter" produced by (Quanser, 2005). The main part of the plant is the helicopter body. It consists of two propellers, each fixed on one end of the same small arm. This arm is connected to the rotator arm using the rotator arm as an axis. This movement is called pitch and it's angle is described by $\theta$. The rotator arm is connected to the base arm. The movement between these two 
is called elevation $\psi$ (rotates about the horizontal axis). Finally the base arm is connected to the base. As the others it can rotate too. This rotation is about the vertical axis. The angle is $\phi$ and is called travel. The plant has two inputs: the input voltages to each of the two power amplifiers (DC motors), that turn the propellers. The maximum input voltage to the motors is $5 \mathrm{~V}$. The movement is measured by three digital angle encoders. The pitch and elevation angles have an encoder resolution of 0.088 degrees and the encoder resolution of the travel angle is 0.044 degrees.

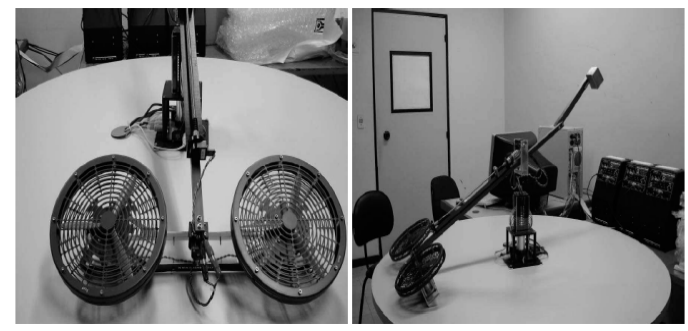

Figure 1: 3DOF Helicopter (Quanser).

The plant is represented by a nonlinear sixthorder model developed in (Lopes, 2007) and redefined in (Maia, 2008). Due to the encoders the plant also shows a quantization effect, however this negligible effect is not included in the model. The model has the form shown in Eq. (1), where $x_{1}$ is the pitch angle (in rad), $x_{2}$ is the pitch rate (in $\mathrm{rad} / \mathrm{s}$ ), $x_{3}$ is the elevation angle (in rad), $x_{4}$ is the elevation rate (in rad/s), $x_{5}$ is the travel angle (in $\mathrm{rad}$ ), $x_{6}$ is the travel rate (in $\mathrm{rad} / \mathrm{s}$ ), $u_{1}$ is the front motor amplifier input voltage (in V), $u_{2}$ is the rear motor amplifier input voltage (in V), and the remaining symbols represent constants determined experimentally (Maia, 2008).

$$
\begin{aligned}
\dot{x}_{1}= & x_{2} \\
\dot{x}_{2}= & \xi_{16}\left\{\xi_{1}\left(u_{1}^{2}-u_{2}^{2}\right)+\xi_{2}\left(u_{1}-u_{2}\right)-\nu_{2} x_{2}\right\} \\
\dot{x}_{3}= & x_{4} \\
\dot{x}_{4}= & x_{6}^{2}\left\{\xi_{3} \sin 2 x_{3}+\xi_{4} \cos 2 x_{3}\right\}+ \\
& +\xi_{5} \sin x_{3}+\xi_{6} \cos x_{3}+ \\
& +\left\{\xi_{7}\left(u_{1}^{2}+u_{2}^{2}\right)+\xi_{8}\left(u_{1}+u_{2}\right)\right\} \cos x_{1} \\
\dot{x}_{5}= & x_{6} \\
\dot{x}_{6}= & \left\{\xi_{13}+\xi_{14} \sin 2 x_{3}+\xi_{15} \cos 2 x_{3}\right\}^{-1} \\
& \times\left\{\nu_{1}-\nu_{3} x_{6}+\right. \\
& +\left[\xi_{9}\left(u_{1}^{2}+u_{2}^{2}\right)+\xi_{10}\left(u_{1}+u_{2}\right)\right] \sin x_{1}+ \\
& \left.x_{4} x_{6}\left[\xi_{11} \sin 2 x_{3}+\xi_{12} \cos 2 x_{3}\right]\right\}
\end{aligned}
$$

For robust control with the TFL/LTR method the model needs to be linearized. The corresponding model was determined by a linearization around an equilibrium point, $\left(x_{e q}=0, u_{1 e q}=\right.$ $\left.u_{2 e q}=2.9735 \mathrm{~V}\right)$ which keeps the helicopter in the horizontal position (Afonso, et. al., 2009). The model matrices $A$ and $B$ are:
$A=\left[\begin{array}{cccccc}0 & 1 & 0 & 0 & 0 & 0 \\ 0 & -0.7530 & 0 & 0 & 0 & 0 \\ 0 & 0 & 0 & 1 & 0 & 0 \\ 0 & 0 & -1.0389 & 0 & 0 & 0 \\ 0 & 0 & 0 & 0 & 0 & 1 \\ -1.3426 & 0 & 0 & 0 & 0 & -0.4377\end{array}\right]$

$$
B=\left[\begin{array}{cc}
0 & 0 \\
2.966 & -2.966 \\
0 & 0 \\
0.4165 & 0.4165 \\
0 & 0 \\
0 & 0
\end{array}\right]
$$

Since the output variables are $x_{1}, x_{3}$ and $x_{5}$ these states represent, respectively, the angles: pitch, elevation and travel.

\subsection{TFL/LTR Method and Specifications}

The TFL/LTR approach for designing a robust controller falls under a broader category of procedures in which the robustness is ensured by certain loop properties (Prakash, 1990). It consists of two sequential steps, namely, TFL design, characterized by calculation of the constant TFL-gain matrix, $K_{f}$, that specifies stability and robustness performance, and the LTR step, with the determination of the constant LTR gain matrix, $K_{r}$, to recover the loop transfer. A block diagram representation of the controller structure TFL/LTR is shown in Figure 2.

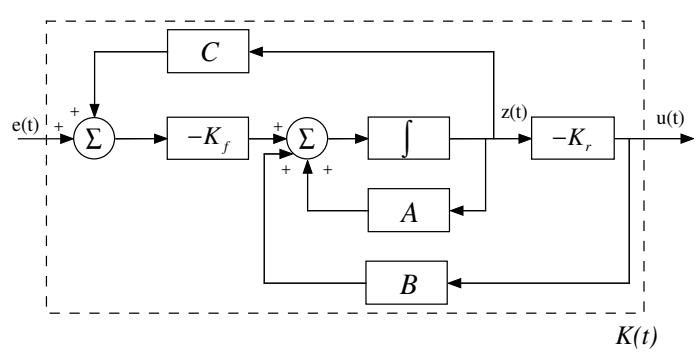

Figure 2: Schematic block structure of the TFL/LTR controller.

The controller equations are,

$$
\begin{aligned}
& \dot{z}(t)=A z(t)+B u(t)+K_{f}[-e(t)-C z(t)], \\
& u(t)=-K_{r} z(t)
\end{aligned}
$$

$K_{f}$ and $K_{r}$ are the gain matrices and $z(t)$ stands for the compensator state vector. In our model we represent the controllers by the matrices $A_{k}, B_{k}$ and $C_{k}$, defined by:

$$
A_{k}=\left(A-K_{f} C-B K_{r}\right) ; B_{k}=-K_{f} ; C_{k}=-K_{r}
$$




\subsection{TFL step with Kalman filter}

A Kalman filter can be used for target feedback loop design (TFL-design). This was shown in (Athans, 1986) and (C. Doyle and Stein, 1981) with the plant being described as:

$$
\begin{aligned}
& \dot{x}(t)=A x(t)+B u(t)+E \xi(t) \\
& y(t)=C x(t)+n(t)
\end{aligned}
$$

The model with $A, B$ and $C$, must be detectable. In addition $C$ has full row rank. $\xi(t)$ and $n(t)$ are both vector processes. $\xi(t)$ is a process noise or disturbance and $n(t)$ mainly measurement noise. The Kalman filter matrix equation is:

$$
K_{f}=\Sigma C^{T} V^{-1}
$$

where $\Sigma=\Sigma^{T}>0$ is the solution of the filter algebraic Riccati equation (FARE)

$$
A \Sigma+\Sigma A^{T}-\Sigma C^{T} V^{-1} C \Sigma+W=0,
$$

with $W=W^{T} \geq 0$ and $V=V^{T}>0$. We get a perfect estimation in steady state for $e(t) \rightarrow 0$ as $t \rightarrow \infty$, if the disturbance noises $\xi(t)$ and $n(t)$ are equal zero.

\subsection{LTR step - Amplified Linear Quadratic Reg-} ulator

Herein, the second step is realized with an amplified linear quadratic regulator (ALQR). The ALQR gain is given by:

$$
K_{r}=(1 / \beta) R^{-1} B^{T} P
$$

where $P=P^{T}>0$ is the solution of the regulator algebraic Riccati equation (RARE)

$$
A^{T} P+P A-P B R^{-1} B^{T} P+Q=0 .
$$

In (9) $\beta$ must be between 0 and 1 (Prakash, 1990). Guaranteed multivariable margins of ALQR can be established when used in state feedback regulator loops, they correspond to the gain/phase perturbation, that can be considered in all the outputs simultaneously or in an independent manner (Prakash, 1990). These guaranteed multi-variable margins are given by:

$$
\begin{aligned}
& G M=\beta / 2, \infty \\
& P M= \pm \cos ^{-1}(\beta / 2)
\end{aligned}
$$

in which, GM is the guaranteed gain margin and $\mathrm{PM}$ is the guaranteed phase margin.

\subsection{Time-delay and loss of power}

In our controller evaluation before the signal is sent to the actuators it runs through two different disturbances, as shown in Figure 3. This is done for robustness evaluation purposes. Initially, the signal gets multiplied by 0.5 . So just $50 \%$ of the

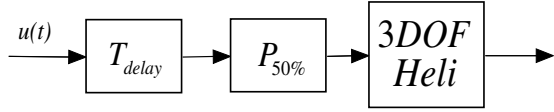

Figure 3: Time-delay and loss of power.

signal for a nominal control gets to the propellers. This simulates a possible loss of power, which in reality can be caused by actuator failure.

The second disturbance is a time delay so instead of sending the signal directly to the plant the signal gets held back for $t_{d}=0.05 \mathrm{~s}$. This simulates a transport delay (such as a communication delay to actuator).

\section{Design of the robust controllers}

To demonstrate the effectiveness of the proposed methodology, two different conditions will be discussed. Experiments will be realized using MATLAB/Simulink in order to verify and compare the performance of the robust controllers using different $\beta$ parameters.

To eliminate the steady state error, integrators are inserted at system output for travel and elevation angle. With insertion of integrators the order of the system increases from 6 to 8 . The goal is to develop a control system to get robust stability and a suitable performance. This was obtained with the following designs for two different values of $\beta$.

\subsection{TFL design}

The weighting matrices of the filter were chosen suitably, so that the singular values of $T_{f}=$ $C(s I-A)^{-1} K_{f}$ provide a good performance and stability. The TFL-gain, $K_{f}$, determined for $W=\operatorname{diag}\left[\begin{array}{ccccc}0.01 & 100 & 0.01 & 100 & \ldots \\ \ldots & 0.01 & 60 & 0.01 & 0.01\end{array}\right]$ and $V=80 I_{5 \times 5}$ :

$K_{f}=\left[\begin{array}{ccccc}4.0325 & 0 & -0.1623 & 0 & -0.0015 \\ 8.1437 & 0 & 0.0740 & 0 & 0.0125 \\ 0 & 4.4270 & 0 & 0.8781 & 0 \\ 0 & 10.1847 & 0 & 0.3318 & 0 \\ -0.1623 & 0 & 3.1643 & 0 & 0.8749 \\ -1.2432 & 0 & 5.4024 & 0 & 0.4726 \\ 0 & 0.8781 & 0 & 0.9925 & 0 \\ -0.0015 & 0 & 0.8749 & 0 & 0.9921\end{array}\right]$

Figure 4 shows the singular values for the target loop. It is noteworthy that the relevant characteristics for the target loop are given by the two main singular values which describe the elevation and travel response $(-20 \mathrm{db} /$ decade or less in low frequencies).

\subsection{LTR design}

The LTR procedure will be performed using ALQR with $Q=q^{2} C^{T} C$ and $R=0.15 I_{2 \times 2}$. 


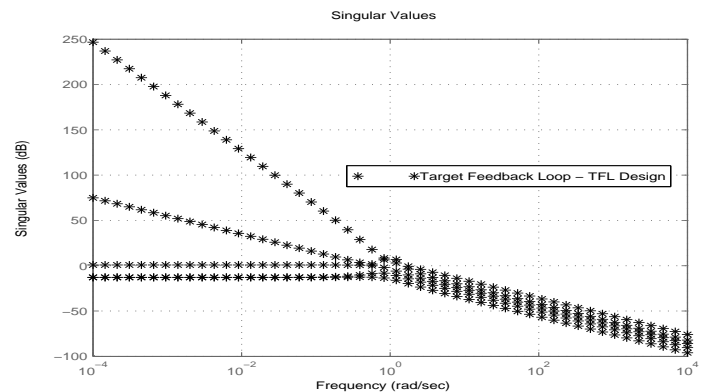

Figure 4: Target Feedback Loop - TFL Design.

The LTR-parameter $q^{2}$ chosen for recovery was $q^{2}=10000$, and $\beta \in\left[\begin{array}{cc}1 & 0.05\end{array}\right]$. The LTR-gains, $K_{r}$, using $\beta=1$ and $\beta=0.05$ respectively are:

$$
\begin{gathered}
K_{r_{\beta=1}}=\left(\begin{array}{cccc}
198.66 & 8.05 & 202.17 & 22.03 \\
-198.66 & -8.05 & 202.17 & 22.03 \\
-401.19 & -284.75 & 182.57 & -182.57 \\
401.19 & 284.75 & 182.57 & 182.57
\end{array}\right) \\
K_{r_{\beta=0.05}}=\left(\begin{array}{ccccr}
3973.2 & 161.1 & 4043.5 & 440.6 \\
-3973.2 & -161.1 & 4043.5 & 440.6 \\
-8024 & -5695.2 & 3651.5 & -3651.5 \\
8024 & 5695.2 & 3651.5 & 3651.5
\end{array}\right)
\end{gathered}
$$

Figure 5 illustrates the recovery obtained for the different $\beta$ parameters.

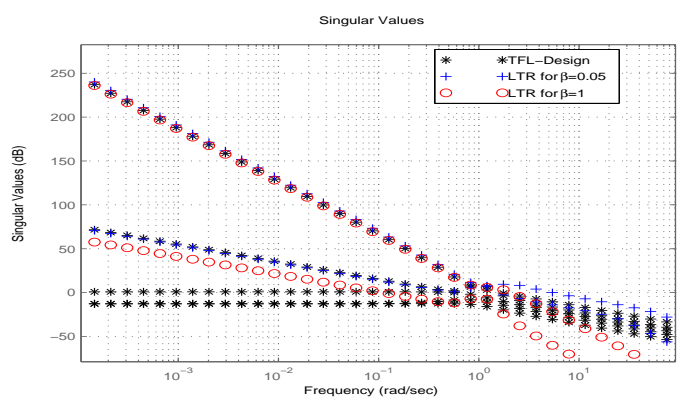

Figure 5: Loop Transfer recovery - LTR design.

Thus the recovery using ALQR-gain with $\beta=$ 0.05 was better than using LQR-gain $(\beta=1)$.

\section{Results and Discussions}

Results are summarized in Figs. 6, 7, 8. The controllers with the described method were tested on the 3DOF-Helicopter, giving an elevation and travel input signal/ set point.

\subsection{Description of the experiment and outputs}

At the beginning $\mathrm{t}=0 \mathrm{~s}$ the helicopter lays on the table. This position is defined as origin of the coordinates (travel $\phi=0^{\circ}$, elevation $\psi=0^{\circ}$ and pitch $\theta=0^{\circ}$, which is different from the linearization point.). After 15 seconds the plant should rise to a height of $\psi=25^{\circ}$. Because the propellers where not moving at all, it takes around 2 seconds to get them to a take off rotating speed. The take off is not completely horizontal. So we also get a small change in travel. Just when the plant reached this angle, it begins to travel to $\phi=120^{\circ}, \mathrm{t}=20 \mathrm{~s}$. During this movement the pitch reaches around $27^{\circ}$. This also has an effect on the elevation. After 45 seconds we have movement on two axes simultaneously. The helicopter rises due to a step signal from $\psi=25^{\circ}$ to $35^{\circ}$ and travels from $\phi=120^{\circ}$ to $180^{\circ}$ within 5 seconds. This has a big impact on the pitch letting $\theta$ oscillate between $27^{\circ}$ and $-17^{\circ}$. From now on there are two slow, but continuous motions bringing the helicopter back to its point of origin. All the measured signals are quite steady with just a small disturbance in pitch and elevation, whenever the angle of travel $\phi=0^{\circ}$ is reached. At $\mathrm{t}=120$ s all the variables are zero again and the input signal stops. If you look carefully at Figure 6 you can see that pitch $\theta=5^{\circ}$ is needed to keep the helicopter steady. This is because both motors and propellers rotate clockwise. This has an impact in form of a moment on the plant, which needs to be compensated.

\subsection{Discussion}

Now the results presented in Figure 6, 7 and 8 are discussed. First of all we can notice right away, that even though the two travel signals do not show big divergences, the pitch and elevation responses of the standard $(\beta=1)$ and of the amplified controller $(\beta=0.05)$ have differences, which are pointed out now. In Figure 6 the pitch angle $\theta$ differences between the two controlled systems in terms of stability and performance become clear.

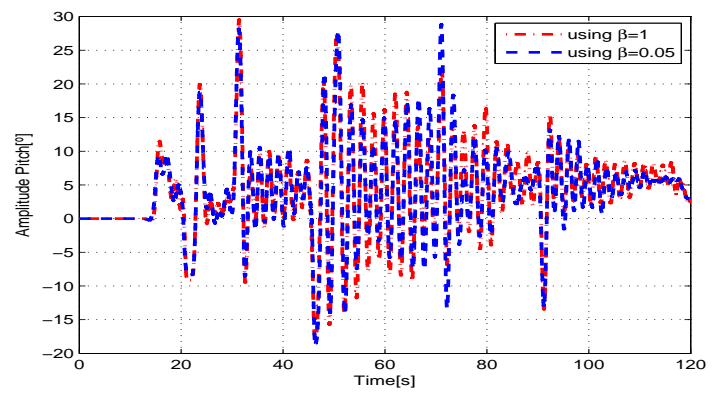

Figure 6: Pitch angle.

As we can see with the standard controller the helicopter needs much longer to go back to horizontal position after every movement. Especially between second 50 and 70 or 90 till 120, pitch oscillates a lot more than with the amplified linear quadratic regulator.

The Figures 7 and 8 show the results for elevation $\psi$ and travel $\phi$ angles. Here we have equivalent results. The ALQR controller leads to a 


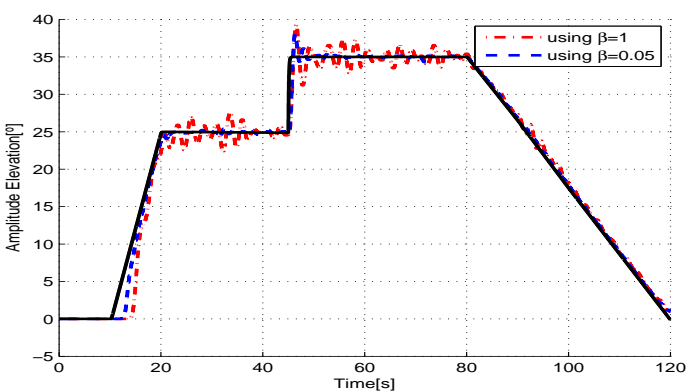

Figure 7: Elevation angle.

less oscillatory motion. Furthermore, the standard controller needs more than a second longer to take of at the beginning, so we also have some performance differences there.

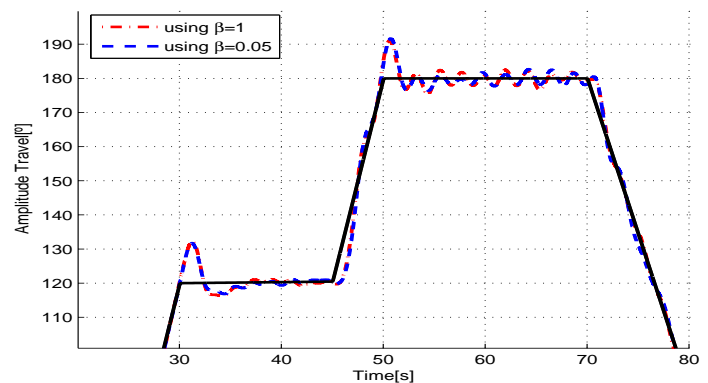

Figure 8: Travel angle.

\section{Conclusions}

The results show, that the Target Feedback Loop/Loop Transfer Recovery structure in combination with the amplified linear quadratic regulator (ALQR) can be very well used to design controllers with a good performance and robustness to delays and power loss. The helicopter in combination with the amplified linear quadratic regulator reacts more directly and with less oscillation especially in pitch and elevation movement. A novel aspect in this paper is that LTR was done with the ALQR instead of LQR.

\section{Acknowledgements}

The authors wish to thank the anonymous reviewers for providing constructive suggestions. The support provided by CAPES, the DitzeFoundation (Germany) and FAPESP (grant 2011/17610-0) is gratefully acknowledged.

\section{References}

Afonso, R. J. M. et al.(2009). Projeto de um controlador robusto para um modelo de um helicóptero com três graus de liberdade baseado no método LQG/LTR, $3^{\circ} C T A-D L R$ Workshop on Data Analysis \& Flight Control.

Athans, M.(1986). A tutorial on the LQG/LTR method, American Control Conference, pp. $1289-1296$.

Cavalca, M. S. M. and Kienitz, K. H. (2009). Application of TFL/LTR robust control techniques to failure accommodation, 20th International Congress of Mechanical Engineering, pp. 1-8.

Cruz, J. J. da. (1996). Controle robusto multivariável, São Paulo: Universidade de São PauloEDUSP.

Doyle J.C. and Stein, G.(1979). Robustness with observers, IEEE Transactions on Automatic Control,Vol. 17, pp. 607-611. DOI: 10.1109/TAC.1979.1102095

Doyle J.C. and Stein, G. (1981). Multivariable feedback design: Concepts for a classical/modern synthesis, IEEE Transactions on Automatic Control, Vol. 26, pp. 4-16. DOI: 10.1109/TAC.1981.1102555

Lopes, R. V. (2007). Modelagem e controle preditivo de um helicóptero com três graus de liberdade, Tese de Mestrado, ITA, São José dos Campos.

Maia, M. H. (2008). Controle preditivo robusto de um helicóptero com três graus de liberdade sujeito a perturbações externas, Tese de Mestrado, ITA, São José dos Campos.

Pereira, R. L. and Kienitz, K. H. (2011). A practical evaluation of robust controllers designed with variants of the LQG/LTR method, 21th International Congress of Mechanical Engineering, pp. 1-9

Prakash, R. (1990). Target feedback loop/loop transfer recovery (TFL/LTR) robust control design procedures, 29 th Conference on Decision and Control, Vol. 3, pp. 1203-1209.

Quanser. (2005). Quanser 3DOF helicopter system (with active disturbance), Canada.

Skogestad, S. and Postlethwaite, I. (2001). Multivariable feedback control: analysis and design, Chichester: John Wiley \& Sons. 